\title{
Opening Doors to Training Medical Toxicology Fellows from All Residency Backgrounds
}

\author{
Louise $\mathrm{KaO}^{1}$ (1) $\cdot$ Michele Burns ${ }^{2} \cdot$ Christine Murphy $^{3}$ - Evan Schwarz ${ }^{4}$ on behalf of ACMT Fellowship Directors \\ Committee
}

Received: 16 November 2021 / Revised: 3 December 2021 / Accepted: 7 December 2021

(c) American College of Medical Toxicology 2021, corrected publication 2022

Medical Toxicology fellowship training is available for graduates of any accredited USA (ACGME) or Canadian (RCPSC/CFPC) residency program, or at the discretion of the program director and institutional review committee [1]. In an ideal world, this should lead to more applicants from outside of Emergency Medicine (EM) applying to Medical Toxicology fellowship programs. While knowledge of and interest in the specialty of Medical Toxicology is part of the issue, having few training options for non-EM applicants can also limit recruiting. Most Medical Toxicology Fellowship programs are housed under EM and train primarily EM residency graduates. Many programs have a shift or service requirement built into the fellowship curriculum, and not every program is able to consider applications from all residency training backgrounds. Over the past 5 years, and currently, about $90 \%$ of US Medical Toxicology fellows have an EM training background [2]. Non-EM applicants to Medical Toxicology fellowships have historically reported difficulty determining which programs would accept their applications [3]. We fear that this may discourage potential applicants from applying to our specialty. In response, several years ago Medical Toxicology fellowship programs developed a document detailing applicant eligibility and the presence of a clinical requirement $[4,5]$. In order to provide even more

Supervising Editor: Mark B. Mycyk, MD.

Louise Kao

Lkao@Iuhealth.org

$1 \quad$ Medical Toxicology Fellowship Program, Indiana University School of Medicine, Indianapolis, IN, USA

2 Medical Toxicology Fellowship Program, Harvard Medical School, Boston, MA, USA

3 Medical Toxicology Fellowship Program, Atrium Health Carolinas Medical Center, Charlotte, NC, USA

4 Medical Toxicology Fellowship Program, Washington University School of Medicine in St Louis, St. Louis, MO, USA information to applicants, the fellowship directors group sought to include information regarding which programs have trained a fellow outside of EM within the past 5 years.

Utilizing an existing ACMT database of current and past fellows, the training background of US Medical Toxicology fellows with graduation year 2015-2021 was queried [2]. These results were reviewed with the 27 Program Directors (PD) of ACGME accredited US Medical Toxicology fellowship programs as of March 2020 to further verify the accuracy of the information conveyed. Of the 27 programs at the time of this review, 20 (74\%) accept applications outside of EM and 21 (77.8\%) have a clinical requirement.

In the past 5 years, not surprisingly, all $(100 \%)$ had fellows from EM, 10 (37\%) had Pediatrics, 7 (25.9\%) had Internal Medicine, 2 (7.4\%) had Occupational/Preventive Medicine, and $3(11.1 \%)$ had another specialty-Family Medicine and Forensic Medicine. Overall, 12 (37\%) of programs had trained a fellow outside of EM within the past 5 years, including 7 (25.9\%) with a clinical requirement (Fig. 1).

For the graduation years of 2015-2021, there were 225 categorical EM fellows, 5 fellows with a combined EM background, and 22 non-EM fellows (9.7\%). Their training backgrounds are individually detailed in Table 1 . This dataset does not verify completion of training; however, we are still able to relate that the fellows of different training backgrounds were eligible to begin their training in the respective Medical Toxicology fellowship programs.

With this data, we seek to inform incoming applicants regarding applicant eligibility at individual programs as well as inform the medical toxicology community at large regarding these demographics. We find it encouraging that 12 of 27 programs, even those with a clinical requirement, have trained fellows outside of EM in the past 5 years. The importance of recruiting fellows from outside of EM has been discussed, most recently from the perspective of a pediatrictrained toxicologist [3]. 
Fig. 1 Number of programs with MT fellows from each residency background 2015-2021.
Table 1 Individual training background details.

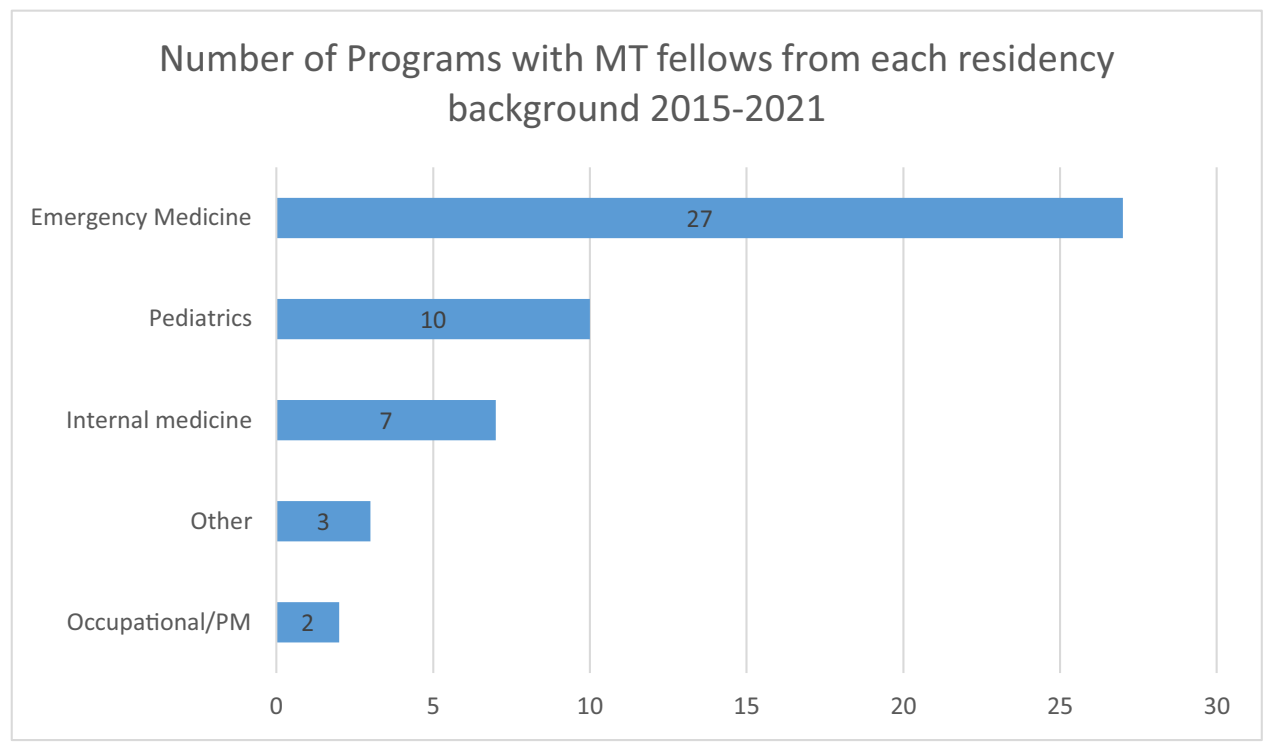

\begin{tabular}{|c|c|c|c|}
\hline Program & Specialty & Grad year & comments \\
\hline University of Arizona - Banner Health & Family Medicine & 2015 & \\
\hline University of Virginia—Charlottesville & IM & 2015 & \\
\hline Rocky Mountain Poison and Drug Center & IM & 2015 & International \\
\hline University of Arizona - Banner Health & IM/Pediatrics & 2015 & \\
\hline Health Partners Institute-Regions & EM/IM & 2016 & \\
\hline University of Texas-Southwestern & EM/IM & 2016 & \\
\hline University of Texas-Southwestern & Pediatrics & 2016 & \\
\hline University of Arizona - Banner Health & IM/Pediatrics & 2016 & \\
\hline New York University & Pediatrics/PEM & 2016 & \\
\hline Health Partners Institute-Regions & Pediatrics & 2017 & \\
\hline Harvard Medical Toxicology & Pediatrics & 2017 & \\
\hline Emory University & Pediatrics & 2018 & \\
\hline Health Partners Institute-Regions & Pediatrics & 2018 & \\
\hline New York University & Pediatrics/PEM & 2019 & \\
\hline SUNY Upstate Medical University & Occupational Med & 2019 & \\
\hline Drexel University & EM/Family Med & 2019 & Closed \\
\hline Emory University & Family Medicine & 2019 & \\
\hline Rocky Mountain Poison and Drug Center & Pediatrics & 2020 & \\
\hline Virginia Commonwealth University & $\mathrm{IM}$ & 2020 & \\
\hline Rocky Mountain Poison and Drug Center & Forensic Medicine & 2020 & International \\
\hline University of Arizona - Tucson & Pediatrics/EM & 2020 & \\
\hline $\begin{array}{l}\text { Barnes Jewish Hospital and St Louis Children's } \\
\text { Hospital }\end{array}$ & Preventive Med & 2020 & \\
\hline Carolinas Medical Center & Pediatrics & 2021 & \\
\hline University of Virginia—Charlottesville & Pediatrics & 2021 & \\
\hline Emory University & EM/IM & 2021 & \\
\hline Health Partners Institute-Regions & $\mathrm{IM}$ & 2021 & \\
\hline University of Arizona - Banner Health & IM & 2021 & \\
\hline
\end{tabular}

EM Emergency Medicine, IM internal medicine, PEM Pediatric Emergency Medicine (fellowship) 


\section{Training Fellows Outside of Emergency Medicine}

A common barrier to training Medical Toxicology fellows outside of EM is related to a clinical requirement whereby fellows must provide a certain number of hours of service in the Emergency Department, frequently to contribute to the funding stream for the position. Programs with a clinical requirement who have successfully navigated training nonEM fellows have relied upon a variety of mechanisms. First and foremost, it is imperative to have collaborative agreements with the respective departments with which the fellow will be engaged. Ideally, these agreements exist in advance of our abbreviated Medical Toxicology fellowship interview season. The candidate will typically interview with both the Medical Toxicology Department as well as the department in which they would fulfill their clinical requirement. For example, for an applicant with a preventive medicine background, the candidate could work in the hospital's occupational medicine clinic and would interview for both the Medical Toxicology fellowship and for their position in the preventive medicine department. For an applicant with a pediatric background, the fellow may be able to work with pediatric hospitalists or, if they have Pediatric Emergency Medicine fellowship training, in a pediatric emergency department. For internal medicine, the fellow may be able to work as an internal medicine hospitalist or in an urgent care or outpatient setting. Other opportunities for applicants such as Global Health or Addiction Medicine may exist depending on the institution's capabilities and needs. The Medical Toxicology fellowship director, along with their division and department, would need to assure that these opportunities remain available from year to year along with the application cycle.

Medical Toxicology fellows largely derive from an Emergency Medicine background, and the majority of fellowship programs have a clinical requirement typically accomplished in the Emergency Department. Some fellowship programs have been successful in providing a clinical requirement for fellows outside of Emergency Medicine. Despite some additional complexity, if these agreements can be accomplished, non-EM applicants would benefit from increasing opportunities for training, and fellowship programs would benefit from expanding their reach within their institution. The specialty of medical toxicology will continue to evolve and thrive with the benefit of increased diversity of training among medical toxicologists.

\section{Acknowledgements ACMT Fellowship Directors Committee:}

Steve Aks

Kavita Babu

\author{
Gillian Beauchamp \\ Rana Biary \\ Michele Burns \\ Nathan Charlton \\ Cathleen Clancy \\ Jonathan Ford \\ Robert Hendrickson \\ Christopher Hoyte \\ Jeena Jacob \\ Louise Kao \\ Andrew King \\ Mark Kostic \\ Daniel Lasoff \\ Brent Morgan \\ Christine Murphy \\ Joshua Nogar \\ Ayrn O Connor \\ Todd Phillips \\ Anthony Pizon \\ Evan Schwarz \\ Farshad Shirazi \\ Serge Emile Simpson \\ Silas Smith \\ Craig Smollin \\ Ross Sullivan \\ Jenna Wilkinson \\ Brandon Wills
}

\section{Declarations}

Conflicts of Interest The corresponding author is the current President of ACMT and the last author is currently a member of the ACMT Board of Directors.

\section{References}

1. ACGME program requirements for graduate medical education in medical toxicology. 2020 Accreditation Council for Graduate Medical Education. Available at: https://www.acgme.org/globa lassets/PFAssets/ProgramRequirements/118_MedicalToxicolo gy_2020.pdf?ver=2020-06-29-161620-337\&ver $=2020-06-29$ 161620-337. Accessed 29 Aug 2021.

2. ACMT fellows in training membership database, accessed June 2021

3. Ross JA. The role of pediatrics in medical toxicology: a fellow's perspective. J Med Toxicol. 2021;17(4):327-9. https://doi.org/10. 1007/s13181-021-00852-5.

4. Kao L, Pizon A; ACMT fellowship directors committee. medical toxicology fellowship training is available to applicants from many specialties. J Med Toxicol. 2018 Sep;14(3):177-178. https:// doi.org/10.1007/s13181-018-0664-6.

5. American College of Medical Toxicology. Medical toxicology fellowship programs 2021. https://www.acmt.net/_Library/Fello wship_Programs/MT_Fellowship_Programs_Grid.pdf. Accessed 29 Aug 2021.

Publisher's Note Springer Nature remains neutral with regard to jurisdictional claims in published maps and institutional affiliations. 